\title{
The Effect of College Communities on the Employment Cultivation of Technical Applied College Students
}

\author{
Xin Chen, Ying Hu, Xuewei Bi \\ Jiangsu Vocational Institute of Architecture Technology, Xuzhou Jiangsu 221116
}

Keywords: Community, Technical applied type, Employment ability training, Effect.

\begin{abstract}
In recent years, China's teaching investment in higher education has been increasing year by year. Various levels of colleges and universities have carried out different enrollment expansion. The situation of college students' "hard-to-find talents" has been gone for a long time. The number of college graduates every year is 10 million. Many college students are faced with the "graduation is unemployed" predicament. As an important platform for college students' internal activities, the college community is an important way for students to participate in social practice activities. The campus community activities are good at mobilizing students to participate in and enhancing students' individual ability and quality. In the technical applied higher institutions, on the basis of professional technical teaching, through targeted community activities, they explore the second classroom which cultivated by the students' ability to promote their personal professional competence and professional quality and to highlight the effect of community in the employment of technical applied college students.
\end{abstract}

\section{Introduction}

According to the Statistics data from National Bureau, in 2016 there are 7.65 million college graduates more than 16 million in 2015. A record number of graduates, college students employment difficulties will be greatly increased at all levels of society, when they mobilize multi-faceted efforts to promote employment of college students, colleges and universities should also strengthen their ability to cultivate students' employment ability, tap the employment potential of students and improve the quality of students. Nowadays, in the process of hiring graduates, recruitment-oriented enterprises not only pay attention to the students' learning ability and academic achievement, but also pay more attention to the students' social adaptability. As the students' important organizations, college communities are an important platform for students to participate in social practice and exercise personal interpersonal skills. College community as a carrier to develop ability of students in new era can cultivate their employment ability, so that students win in the fierce employment competition. By analyzing the connotation of college associations and the employment predicament of college students with technology application in the new era, this paper is analyzed the shortcomings of the current technology-applied college societies in cultivating students' employment ability, correcting them, exploring new ways to promote the employment of college graduates, and playing the role of college communities on the cultivation employment ability of technical applied college students. First, outline of college communities and college students employment ability.

\section{The Scientific Connotation of College Communities}

To fully understand the functions of the community to understand and maximize its function must have a very good understanding to its meaning. At present, China's accurate definition of college community groups has not yet reached a consensus, Baidu defined it as the organization which are gathered together by people who have the common characteristics for mutual benefit and mutual benefit in some aspects. The college community is defined as the mass organizations for college students who have individual subjective wishes on the basis of the freedom. ${ }^{\mathbf{1} 1}$ In the 
perspective of college education, student community is the establishment for assisting school education and teaching, as well as it can promote the development of students' personal interests, the display of individual talent, personal ability to exercise and other functions, such as academic society, part-time club, drama club, photography club, lecture club, dance club, basketball club, roller skating club, soccer club. There are some features, such as freedom, openness, diversity, mutual benefits in college communities. The first feature is the freedom. The common elements of these communities are based on the establishment interests of students in the school. Student organization can be established after the approval of the relevant leading departments and it can make college life more diversified, give students the stage to show their own, and promote the development of personal ability and interest of students. The composition of the community is spontaneous without the compulsive factor in which each member enjoys the autonomy. This malpractice of freedom is the school supervisory unit has no time to guide the development of too many kinds of communities. Second, openness, as a member and the organization of school students, colleges communities in the service activities carried out not only in the face of the school teachers and students, but also have appropriate contact with social tasks, such as: taking part in community activities, learning from Lei Feng activities, volunteer activities. Third, diversity, there are various kinds of college communities, involving the arts, humanities, geography, history, academic, miscellaneous arts and other aspects. Fourth, mutual benefits, students participate in the process of community activities. Through personal participation they can better understand the current social situation and the employment environment and better exercise their personal communicative abilities in the process of practice exercise. As a collective organization, students who participate in the construction process of community management can better understand the meaning of team collaboration, and on this basis increase the capacity of individual team.

Employability was first proposed by a British economist at the beginning of the last century. After a century of change, the structure, content, environment and policy and many other aspects of employment in society have a significant change. With social change, the meaning of employability has also been a more specific definition. ${ }^{\mathbf{2} \mathbf{1}}$ That is that workers have access to and maintain the ability of personal work. For college students, it refers to the skills which achieve the personal desire, meet the demand of employment and achieve personal value in employment and life are qualified after learning of personal knowledge abilities, skills, qualities through the systematic knowledge in school. His performance is not only in the school you have achieved the examination results, those who can not be on the surface of the assessment ability, communication skills, teamwork, adaptability, resilience and so on are in its scope. As a college student with the appropriate standard of employability is the ability to survive for a college student to acquire. In the completion of the corresponding school year after the study, college students should be able to rely on individuals in the learning process accumulation precipitation things to move employers and to get a desirable job, and in the follow-up work to be sure and praise. However, looking at the contemporary Chinese college students are very few who are fully equipped with the ability. Many college students are facing the "graduation or unemployment" predicament. The emergence of this situation not only related with the social employment situation, but more importantly also lacked of the individual employment ability of college students.

\section{The current employment difficulties faced by Chinese college students}

At present, college students are facing with more severe employment situation. With the lower threshold to entrance of higher education in China, the number of college graduates increased dramatically, compared to the growth of current labor market demand for human is slow, making an imbalance between supply and demand in the job market. ${ }^{\mathbf{3} \mathbf{1}}$ As the financial crisis, the global economic downturn, China's economy experienced rapid growth after more than 20 years has gradually slowed down, making the business development difficulties that more and more medium and small enterprises are facing business difficulties in the brink of bankruptcy and collapse and the needs of talent market are be reducing. 
In addition, due to China's recent increase in the strength of industrial restructuring, many labor-intensive industries have carried out a different range of layoffs. These unemployed people are also involved in the employment competition for graduates, so that the already severe employment environment becomes even worse. At present, China's traditional processing enterprises are no longer the rapid momentum growth, replaced by the rapid development of high-tech industry. These high-tech enterprises have a great need for high-quality skilled personnel. But due to the impact of education structure, China's higher education consider ordinary knowledge-based personnel as training objectives, making the contemporary college students in the lack of professional knowledge and skills, while the overall quality of students is not up to the requirements of these high-tech enterprises, which comply with the "quality first" principle in the recruitment process. There appear a group of "hard-to-employment" talents in the employment and the market because those who are not standard candidates will be eliminated. At the same time, many college students in the concept of employment seriously distorted, these spoiled children, accustomed to the life of "stretching hands forward for clothing, and opening mouth for eating.", the blind pursuit of high wages and high welfare enterprises in the process of employment, can not accurately according to the individual personality characteristics, knowledge and skill level select a reasonable business, making them have employment opportunities but can not be employed. A number of factors make the current college students face the plight of employment. However, more importantly, the employment capacity of contemporary Chinese college students is lacking. There are good job positions, but college students do not have the ability to obtain employment. So the predicament of employment appeared naturally.

Third, the role of community in the cultivation of employment ability of college students

The predicament of employment of contemporary college students makes the university education management departments have to propose mitigation strategies, to strengthen cooperation with employers, targeted personnel training mode and to increase the beginning of the application of professional and other measures. But in order to fundamentally change the predicament of employment of college students, enhancing students' individual employment ability is the most fundamental path. ${ }^{\mathbf{4} \mathbf{1}}$ University communities have gone through a long course of development and have unique role on the cultivation of employability of students. Through participation in school community, as a free organization, students can better understand and position themselves. The main reason for participation of students in the community is personal interests and expertise requirements, although the community is a small group of students within the organization, its organizational integrity, management, outreach, planning, operations and other areas are available. The students can be led by personal interests, can exercise personal "work experience" for the future employment, and can better integrate to the society, the workplace to enhance personal employability.

The lack of social experience of the college students, the scope of interpersonal friends mostly confined to the student group, which makes them lack of communication in the expression, such as individual language, logical thinking ability, expression, attitude. Some introverted students may be afraid to speak in public or in front of the crowd, with blush, trembling. It is clearly inappropriate for an employee who wants to work independently at his own position, and this is point that the university students must change. Although the school will open the relevant language teaching curriculum for students in the daily learning courses, the intensity of the language training learning not really meets the needs of the work. College community, as the media platform between student classroom and life, provides students with a close-to-real communication environment by participating in various activities in the course of the operation, such as drama communities, dance communities, academic clubs and speech debates clubs. A variety of community activities provide close to the actual communication environment. Students can express personal views and adopt the views of others with other members of mutual exchange of views participate in accordance with the corresponding activities of the law when they take part in these activities organized by the community. Through this practice activities accumulated training, it can enhance personal communication skills, make individuals communicate with others more skilled, stable, and help 
them gain employment opportunities in the future job interview with personal language advantages.

Coordinated management is a must in the modern enterprise management. The employer thinks highly of student cadres who have management experience from student union in the process of recruitment, compared to ordinary students, these students are adapt to the actual management of enterprises through individual participation in the student union management operations. For the employer, such students have plasticity in the latter part of the job. However, college students' union will be able to provide a small number of positions after all, it can not meet the needs of most students, while colleges and universities communities can be appropriate to make up for this limitation. The school can also run a number of organizations of personal organization and management training to provide more opportunities for college students. Since 2005, the Communist Youth League Central Committee issued a document on the promotion of the development of college societies, the college community has a greater improvement in the operating mode, autonomy, school support efforts and student in management of the community has greater autonomy. The internal rules and regulations are jointly developed by the community groups, and in the community management, they adopt the general management system in turn, so that each member can be familiar with the management of internal operations, decision-making, financial reporting, personnel appointment and removal and many other management content. Initiative of the members can be mobilized under this model that can be a good training of students' organizational management skills to improve the employment of college students. ${ }^{\mathbf{5 1}}$

At present, primary and secondary education in China will adopt the teaching mode of liberal arts and science. The students who are trained in this teaching mode are too single in personal knowledge structure. Partial liberal or science is more common. Technology applied colleges and universities as an open organization in school, with a variety of features, both emphasis on the liberal arts community, and purely mathematical nature of the community, in these societies coexist in science and liberal. The survey shows that the nature of liberal arts college communities accounting for $45.3 \%$ of the total, and the number of Chinese students in the communities of science is $43.5 \%$. In the day-to-day activities of the communities, the students of Arts and Science are involved in the process of thinking, logical thinking ability and liberal arts students carefully combined with the style of doing things, can be a good change in the students' knowledge structure, so that students participate in community to learn knowledge not from the classroom content, and students have access to more comprehensive knowledge, which broaden the students' horizons, enriched their experience, and promoted the technical application of the overall quality of students.

Fourth, to better play the role of community on the employment of technical applied college students

To improve the management system of community activities and to enhance the management capacity of college students. At present, the most common problem in the college community is the lack of the existing organization and management system. The main responsible persons of the community are a number of students. The original intention of establishment of school community is to serve the same interest in students, but students in the management of the organization lack of experience in running. In addition, the various types of colleges and universities within the community, the leader of the school has the limited energy in school management of the community, so the management and operation have lack of a perfect system. Therefore, it is necessary to change the current situation of the college communities. The school should construct professional organization and management departments to coordinate the planning and management of the campus community, establish a perfect community management system, improve the rules and regulations, develop reasonable incentives and measures to establish a stable internal promotion channels. So that organizations in the daily process of operation have strict rules and regulations can be followed, but also make the community in the operation and management process more efficient. The aim is to create a good management organization platform for the community participants, to fully mobilize the enthusiasm of the community participants, participate, and to promote the ability of organizational management of students.

The needs of contemporary enterprises for talents are no longer confined to high-skilled 
personnel and high level of knowledge of talent, it require more with a higher overall quality of talents. For technical applied students, they not only have solid professional skills, but also are able to have multi-disciplinary knowledge of computer, English and other. Contemporary college students have a high degree of mental acuity and strong learning ability, but at the same time they are faced with the problem of weak practical ability. At present, there are many communities which involve the practical and operational ability of college students, such as the computer communities, the intelligent car communities, the science and technology communities, the model college student communities and so on. The existence of these practical communities to some extent strengthens the students in the practical operation, make the technical applied students can apply the theory of knowledge in the classroom into practical activities, gives technology application-oriented college students to create more skills competition platform, and enhance their practical ability.

Good communication skills are an important way to display individual talents. Students with strong technical applied ability are first-class in their professional knowledge ability, but they also face the difficulties like science students, that weak expression ability. There is a widespread language expression is not clear, logical confusion, fear of expression problems. It is very unfavorable for them to display their personal abilities normally. The speech-speaking communities, debating communities, language communities and other language expression training communities in colleges and universities are regularly present in schools. These competitions are a good platform for students to exercise their personal expression skills. Through these platforms students can learn the language knowledge that they can not learn in the language classroom. The students' ability to express themselves on the spot, the ability to resist stress, the ability to adapt can be exercised have great help to promote the ability and enhance the expression of college students.

Entrepreneurial support is one of the key contents of the current college students' employment work. Through the incubation park in the school, the potential entrepreneurial projects are cultivated in the campus to create a batch of student businessmen. As an important platform for students to show themselves, college communities should follow the trend of the times in the process of construction and development. Only by grasping the main points of factors of students' interest, colleges and universities should actively attract more students to participate in community activities. The students can have more opportunities to contact with the society, at the same time, promoting the formation of student groups. In organizing community activities will inevitably involve the issue of sponsor support. Students can use these contacts with the social industry opportunities to explore market opportunities, relying on a small group of individual communities, so that communities become entrepreneurship incubator base to enhance the entrepreneurial capacity of students.

\section{References}

[1] Liu Sicong. The Construction of Students' Communities in Colleges and Universities Based on the Growing Need of Students[D]. Harbin University of Science and Technology .2015.

[2] Wang Haifeng. Based on the Improvement of Employment Capacity of College Students Community Building Research[J] Science and Education, 2015 (6): 21-23.

[3] Wu Huifang. Fujian University Graduate Employment Market Construction and Maintenance[J]. Journal of Zhangzhou Polytechnic College, 2010 (4): 122-127.

[4] Wang Yongjun. Study on Teaching and Employment Service Mode Centered on Enhancing the Employment of College Students[D]. Shandong University, 2010.

[5] Cui Yijun, Gao Yuan. On the Relationship between College Student Communities Activities and the Employment Competitiveness of Graduates[J]. China University Students' Employment, 2007 (15): 25-26. 